Article

\title{
Do You Care for Robots That Care? Exploring the Opinions of Vocational Care Students on the Use of Healthcare Robots
}

\author{
Margo A. M. van Kemenade ${ }^{1, *}$, Johan F. Hoorn ${ }^{2,3}$ and Elly A. Konijn ${ }^{2}$ \\ 1 Faculty of Engineering Design \& Computing; Department of Engineering \& Business, \\ Inholland University of Applied Sciences, Bergerweg 200, 1817 MN Alkmaar, The Netherlands \\ 2 VU University, Faculty of Social Sciences, Department of Communication Sciences, De Boelelaan 1105, \\ 1081 HV Amsterdam, The Netherlands; e.a.konijn@vu.nl (E.A.K.); csjfhoorn@comp.polyu.edu.hk (J.F.H.) \\ 3 Department of Computing and School of Design, The Hong Kong Polytechnic University, Hong Kong, China \\ * Correspondence: margo.vankemenade@inholland.nl; Tel.: +31-629016824
}

Received: 7 February 2019; Accepted: 15 March 2019; Published: 21 March 2019

check for updates

\begin{abstract}
Background: There has been a rapid increase in the population of senior citizens in many countries. The shortage of caregivers is becoming a pressing concern. Robots are being deployed in an attempt to fill this gap and reduce the workload of caregivers. This study explores how healthcare robots are perceived by trainee care professionals. Methods: A total of 2365 students at different vocational levels completed a questionnaire, rating ethical statements regarding beneficence, maleficence, justice, autonomy, utility, and use intentions with regard to three different types of robots (assistive, monitoring, and companion) along with six control variables: gender, age, school year, technical skills, interest in technology, and enjoying working with computers. The scores were analyzed by MANOVA statistics. Results: In relation to our research questions: All students viewed companion robots as more beneficent than monitoring and assistive robots. Level of education did not lead to any differences in appraisal. Participants rated maleficence lowest and the highest scores were given to autonomy and utility, meaning a positive evaluation of the use of healthcare robots. Surprisingly, all students rated use intentions low, indicating a poor motivation to actually use a robot in the future, although participants stated a firmer intention for using monitoring devices. Conclusion: Care students find robots useful and expect clients to benefit from them, but still are hesitant to use robots in their future practice. This study suggests that it would be wise to enrich the curriculum of intermediate care education with practical classes on the use and ethical implications of care robots, to ensure that this group of trainee care professionals fully understand the possibilities and potential downside of this emerging kind of healthcare technology.
\end{abstract}

Keywords: healthcare robots; vocational care students; use intentions; utility; maleficence; beneficence

\section{Introduction}

The rapid increase in the number of older adults (75 years old and up) is a major concern of the developed countries [1]. In the 1950s, the probability that an 80-year-old would survive to age 90 was $15-16 \%$ for women and $12 \%$ for men. By 2002 , this percentage had increased to $37 \%$ and $25 \%$, respectively. Since 1840, female life expectancy has increased by approximately two years per decade, worldwide. This linear growth has yet to stagnate and therefore implies that 'the human life span is not closing in on its limit' [2]. Life expectancy at age 20 is predicted to increase by approximately one year per decade for females and males between now and 2040 [3]. Compared to the working-age population, the proportion of older adults will eventually grow to a point where there are not enough 
people, let alone professional care-givers, to care for the elderly [4-6]. It seems impossible to continue organizing eldercare in the same way as before [7]. Thus, the search for innovative solutions has become crucial, and the deployment of robots in healthcare seems to be a promising way forward [8-13]; however, robot care is not without some controversy.

Care-robotics can be divided into three types: companion, assisting, and monitoring robots [6]. Assisting robots are used to help patients with their daily tasks (e.g., washing and dressing) and monitoring robots are used to keep an eye on the patient (e.g., medicine intake, fall detection). Companion robots are designed to counter social isolation and loneliness. Most people, however, feel uncomfortable with such robots [14], and if care professionals are hesitant from the start, a possible game changer may be lost without having been properly tried and tested.

A previous study elaborated on the effects of education on moral considerations regarding care technology in a quantitative examination among higher and lower educated care professionals [15]. This previous study found that the acceptance of robots in care was more strongly associated with the participants' moral considerations than with utility. Hence, the current study aimed to further explore the educational context and conduct research within the group of vocational educated students. We wanted to collect and examine the opinions of students of care and welfare programmes of Dutch Vocational Educational Institutes, because they are the care professionals of the future. Students in healthcare will form a large part of the group of care professionals that, in the future, will work with this kind of technology [16].

Whereas the previous study [15] explored the possible differences between intermediate and higher vocational educated students in care, this current study will examine educational differences within the group of intermediate vocational educated students. In the Netherlands, intermediate Vocational Education and Training (VET) is called Middelbaar Beroeps Onderwijs (MBO). VET is the main supplier to the labour market and is often regarded as the 'foundation of the economy' or the 'backbone of society'. Approximately $40 \%$ of the Dutch working population has completed a vocational curriculum to at least an intermediate vocational training level [17]. Intermediate vocational training is divided into four levels in the Netherlands. VET offers programmes on four different levels, ranging from the entry level to the middle-management level. Thus, it is interesting to study whether or not educational differences within the different levels of VET lead to different appraisals of care robots.

Therefore, in the current study, we attempted to quantify the various opinions of Dutch vocational care students on care robots from the perspective of the four principles of biomedical ethics [18]: beneficence, non-maleficence, justice, and autonomy. From a technology acceptance perspective, we added 'expected utility of the robot' and 'intentions to use the robot' to this list. Since age, skillfulness, and interest in technology also contribute to opinion formation [19-21] we studied these variables as well for their possible moderating effects.

Beauchamp and Childress [18] have proposed a system of moral principles in the practice of medicine. Maleficence is derived from the principle of "non-maleficence", which states that technology should "first, do no harm" (primum non nocere). For many, this is the paramount principle of biomedical ethics. Beneficence holds that technology should promote the well-being of the patient. Justice is a concern for fairness and equality, while autonomy is the patient's right and ability to freely make decisions about medical treatment. In this study, we aimed to identify which of these principles dominated the moral considerations regarding robots among trainee care professionals. Our research question, then, is:

How do care and welfare students at diverse levels of vocational education differentially evaluate healthcare robotics in relation to their daily routines?

We used the following sub-questions:

RQ-1: Do prospective care professionals perceive different types of robots (Assistive, Monitoring, and Companion) differently in terms of occupational ethics (Beneficence, Maleficence, Justice, Autonomy)? 
RQ-2: Do perceptions of healthcare robots differ between vocational students at lower and middle levels? Related, do they perceive the various robot types differently?

RQ-3: How do prospective care professionals evaluate care robots in terms of utility and possible use intentions? Related, how do these evaluations differ per robot type?

\section{Methods}

\section{Participants}

Students of three different Dutch vocational care programs-Helping Care and Cure, Helping Extramural Care and Nursing-volunteered in a questionnaire study. To acquire as many participants as possible, managers of seven different vocational education and training institutes distributed our online Qualtrics questionnaire ${ }^{1}$ by forwarding an invitation and link to their students in care. A total of 2365 eligible students completed the questionnaire. This number represents $3.9 \%$ of the population of all registered $(61,244)$ lower and middle vocational care students in the Netherlands [22]. On average, there are 5000 students per institute of which $30 \%$ follows an education in care [23,24]. That would make a total possible response of 10,500 participants. Therefore, a rough and conservative estimate of our sample response rate is $23 \%$. All participants remained anonymous. The incentive for participation was one of five gift vouchers of $€ 50$ that were raffled among the participants.

\section{Data Collection}

Participants received a link to an online questionnaire that was specifically developed for this study. The questionnaire had three versions, one for assistive, one for monitoring, and one for companion robots; each version consisted of 39 questionnaire items. The items per robot type were identical so they could be compared. Demographics were probed using seven additional questions.

After opening the link in Qualtrics (Version 24(892), Provo, UT, USA)a brief introduction and consent form was presented. Upon agreement, the participant could commence the questionnaire. Participants were randomly assigned to one of the three versions. The questionnaire opened with a picture of a healthcare robot (Figure 1) followed by a brief description of its capabilities and the tasks it could execute (e.g., reading aloud, exercise coaching, or reminding of medicine intake).

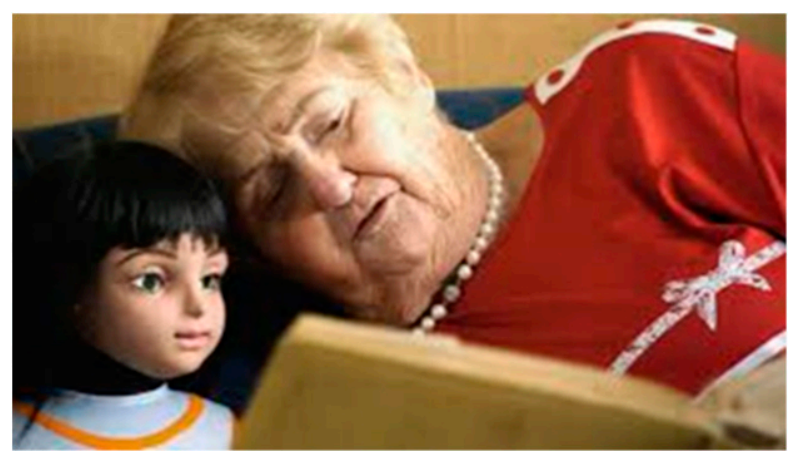

Figure 1. Picture of a companion robot, with courtesy from 'Alice Cares' [25].

\section{Measures}

We measured six theoretical variables, which as a group we will term appraisal domains (i.e., perceived beneficence, maleficence, justice, autonomy, utility, and use intentions), four educational levels (levels 1-4), and three robot types (assistive, monitoring, and companion) along with six control variables: gender, age, school year, technical skills, interest in technology, and enjoying working with computers. Education Level was an ordinal variable: lower vocational education (levels 1 and 2) and middle vocational education (levels 3 and 4). The theoretical variables were measured at quasi interval level with initially six Likert-type items, each rated on a six-point scale $(1=$ strongly disagree, 
$2=$ disagree, $3=$ slightly disagree, $4=$ slightly agree, $5=$ agree, and $6=$ strongly agree). Principal Component Analyses and Reliability analyses revealed that several items had to be discarded to form reliable scales. The questionnaire items that were included per appraisal domain can be found in Appendix A. Scale reliabilities were calculated with Cronbach's alpha as reported in Table 1, using 0.7 as the cut-off point to decide whether a scale was sufficiently reliable or not [26]. The Justice scale failed the 0.7 criterion and had to be discarded entirely. Apparently, the way we measured justice did not converge into a solid underlying concept. All other scales performed well (Table 1). After recoding the counter-indicative items, the items on each scale could be summed and averaged to calculate a mean index (Table 1).

Table 1. Descriptive statistics and reliability analysis, $N=2325$.

\begin{tabular}{|c|c|c|c|}
\hline & Mean & SD & Cronbach's Alpha \\
\hline \multicolumn{4}{|l|}{ Appraisal Domains } \\
\hline Beneficence & 3.640 & 1.088 & 0.88 \\
\hline Maleficence & 2.788 & 1.088 & 0.82 \\
\hline Autonomy & 3.818 & 0.832 & 0.78 \\
\hline Utility & 3.868 & 0.929 & 0.79 \\
\hline Use Intention & 3.080 & 1.190 & 0.90 \\
\hline Justice & - & - & 0.57 \\
\hline \multicolumn{4}{|c|}{ Percentage } \\
\hline \multicolumn{4}{|l|}{ Gender } \\
\hline Female & \multicolumn{2}{|c|}{92.9} & - \\
\hline Male & \multirow{2}{*}{\multicolumn{2}{|c|}{7.1}} & - \\
\hline \multicolumn{2}{|l|}{ Level of Education } & & \\
\hline Vocational Level 2 & \multicolumn{2}{|c|}{9.1} & - \\
\hline Vocational Level 3 & \multicolumn{2}{|c|}{39.0} & - \\
\hline Vocational Level 4 & \multicolumn{2}{|c|}{51.9} & - \\
\hline \multicolumn{4}{|l|}{ Robot Type } \\
\hline Assisting & \multicolumn{2}{|c|}{33.25} & - \\
\hline Monitoring & \multicolumn{2}{|c|}{33.46} & - \\
\hline Companion & \multicolumn{2}{|c|}{33.29} & - \\
\hline \multicolumn{4}{|l|}{ Skilled with Computer } \\
\hline Yes & \multicolumn{2}{|c|}{93.6} & - \\
\hline No & \multicolumn{2}{|c|}{6.4} & - \\
\hline \multicolumn{4}{|l|}{ Skilled in Technology } \\
\hline Yes & \multicolumn{2}{|c|}{45.8} & - \\
\hline No & \multicolumn{2}{|c|}{54.2} & - \\
\hline \multicolumn{4}{|l|}{ Enjoys Working with } \\
\hline \multicolumn{4}{|l|}{ Computers } \\
\hline Yes & \multicolumn{2}{|c|}{72.3} & - \\
\hline No & \multicolumn{2}{|c|}{27.7} & - \\
\hline \multicolumn{4}{|l|}{ Age } \\
\hline$\leq 16$ & \multicolumn{2}{|c|}{6.5} & - \\
\hline$\overline{17}$ & \multicolumn{2}{|c|}{18.3} & - \\
\hline 18 & \multicolumn{2}{|c|}{19.5} & - \\
\hline 19 & & & - \\
\hline 20 & & & - \\
\hline 21 & & & - \\
\hline 22 & & & - \\
\hline 23 & & & - \\
\hline$\geq 24$ & & & - \\
\hline
\end{tabular}

Although 2365 participants completed the questionnaire, cells were not filled equally. Unfortunately, only 2 participants studied at level 1, which made it necessary to drop that level from our analyses. Then, we had to exclude another 38 participants because they had completed the questionnaire in an unreasonably short period of time (which was recorded by Qualtrics) and/or because they checked the same rating scale answer for each item. That left us with $N=2325$ participants 
in the final analysis. Their characteristics can be found in Table 1. Table 2 provides the means and standard deviations of the appraisal domains.

Table 1 shows that participants were evenly distributed over the three robot types ( $33 \%$ each). Table 1 also shows an overrepresentation of females, although in the care professions that is a valid ecological outcome [27]. Unfortunately, however, over $50 \%$ of the total sample studied at vocational level 4 and a mere $9.1 \%$ at level 2, which seriously jeopardized our questions on differences in perception between educational levels. Almost the entire sample self-reported that they were skilled computer users.

\section{Results}

We calculated the grand mean scores of our measurement scales (Table 2) and ran a GLM Repeated Measures for the 5-leveled within-subjects factor of appraisal domain (beneficence vs. maleficence vs. autonomy vs. utility vs. use intentions) by the between-subjects factors of robot type (assistive vs. monitoring vs. companion) and education level ( 2 vs. 3 vs. 4$)$.

Table 2. Mean scores and SDs on the appraisal domains: B (beneficence), M (maleficence), A (autonomy), U (utility), and UI (use intentions) per robot type: A (assistive) M (monitoring), and $\mathrm{C}$ (companion) in the figure on top. In the Figure below, the mean scores and SDs on the appraisal domains are represented per education level $(2,3 \mathrm{~m}$ and 4$) . N_{\text {-total }}=2325$.
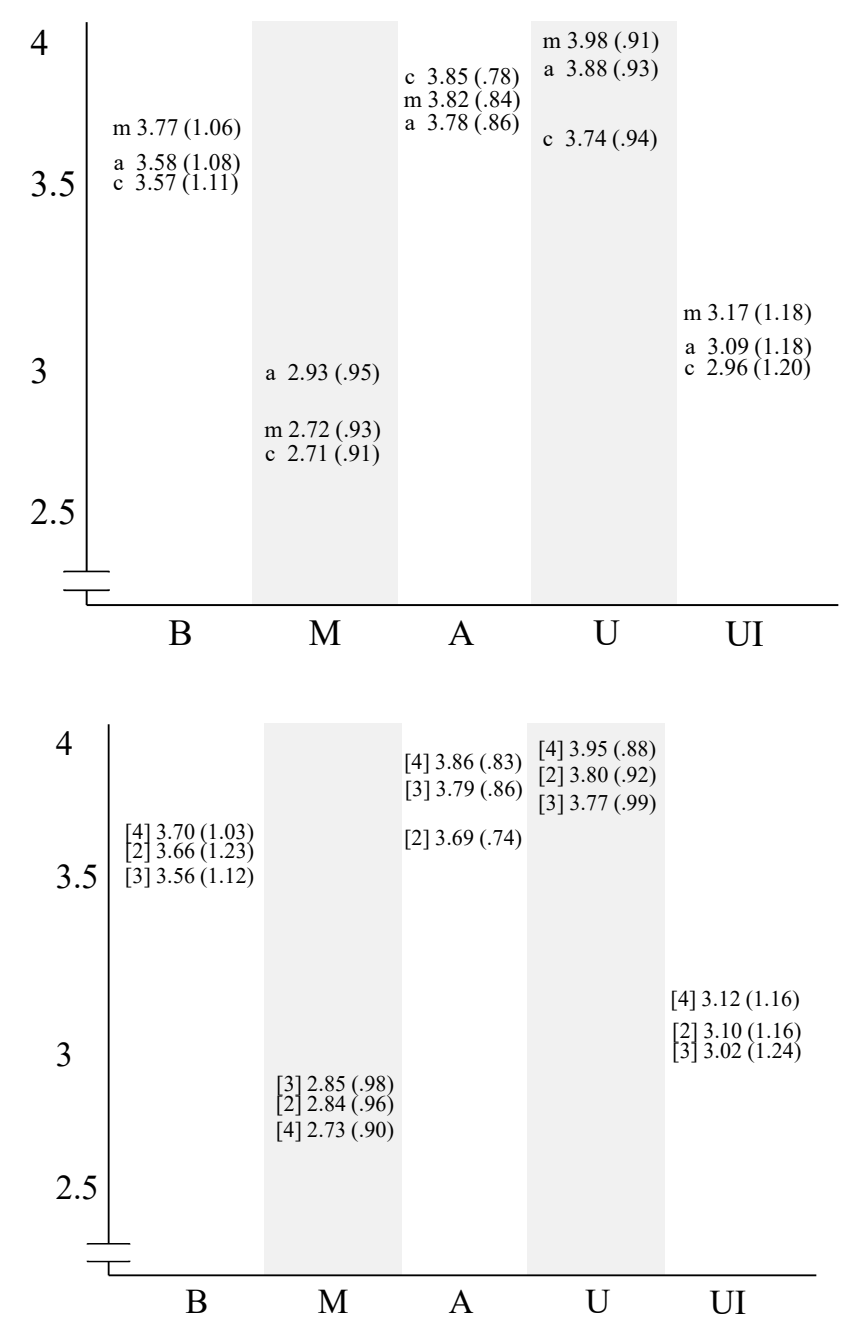


\section{Rating of Appraisal Domains through Ethics}

The interaction between robot type, education level, and appraisal domain was not significant $(p=0.296)$ nor was the interaction between robot type and education level $(p=0.672)$.

However, the main effect of appraisal domain was significant with an intermediate effect size (Wilks' $\left.\lambda=0.53, F_{(4,2313)}=518.67, p=0.000, \eta_{p}{ }^{2}=0.473\right)$, indicating that independent of robot type or education level, participants scored lowest on maleficence $(M=2.81, S D=0.95)$, then use intentions $(M=3.08, S D=1.19)$, then beneficence $(M=3.64, S D=1.13)$, higher on autonomy $(M=3.78, S D=0.81)$, and highest on utility $(M=3.84, S D=0.93)$.

\section{Rating of Appraisal Domains by Robot Type}

The interaction between robot type and appraisal domain was significant $\left(\lambda=0.99, F_{(8,4626)}=4.00\right.$, $\left.p=0.00, \eta_{p}{ }^{2}=0.007\right)$, which was supported by a significant main effect of Robot Type $\left(F_{(2,2316)}=5.23\right.$, $\left.p=0.005, \eta_{p}^{2}=0.004\right)$. To further scrutinize the interaction effect, we ran a number of independent samples $t$-tests (two-tailed) with Bonferroni correction $(\alpha=0.05 / 15$ contrasts $=0.003$ ) [28], indicating that independent of education level, participants deemed monitoring robots more beneficent than assistive robots $\left(t_{(1550)}=3.77, p=0.000\right)$ and assistive robots more beneficent than companion ones $\left(t_{(1549)}=3.59, p=0.000\right)$.

Assistive robots were judged as more maleficent than monitoring robots $\left(t_{(1549)}=4.24, p=0.000\right)$ and more maleficent than companion robots $\left(t_{(1545)}=4.56, p=0.000\right)$. Monitoring robots were perceived as having more utility than companion robots $\left(t_{(1550)}=5.01, p=0.000\right)$ and as a trend, assistive robots were also judged as having more utility than companion machines $\left(t_{(1545)}=2.79, p=0.005\right)$.

Participants indicated higher intentions to use monitoring than companion robots $\left(t_{(1550)}=3.46\right.$, $p=0.001)$. All other comparisons were not significant.

\section{Rating of Appraisal Domains by Educational Levels}

The interaction between education level and appraisal domain was significant as well $(\lambda=0.99$, $\left.F_{(8,4626)}=4.47, p=0.000, \eta_{p}{ }^{2}=0.008\right)$. This interaction was supported by a significant main effect of education level $\left(F_{(2,2316)}=4.69, p=0.009, \eta_{p}{ }^{2}=0.004\right)$. We then ran a number of independent samples $t$-tests (2-tailed) with Bonferroni correction $(\alpha=0.05 / 15$ contrasts $=0.003)$, indicating that independent of robot type, education level 4 students perceived more beneficence than level 3 students $\left(t_{(2111)}=2.94\right.$, $p=0.003)$, whereas level 3 saw, as a trend, more maleficence than level $4\left(t_{(2111)}=2.72, p=0.007\right)$. Level 4 also assigned more utility to robots than level 3 students $\left(t_{(2111)}=4.47, p=0.000\right)$, and as a trend, level 4 thought more than level 2 that robots increased the autonomy of patients $\left(t_{(1417)}=2.81\right.$, $p=0.005)$. All other comparisons were not significant.

\section{Overall Ratings of Appraisal Domains}

In sum, independent of robot type or education level, maleficence and use intentions scored lowest while autonomy and utility scored highest. Independent of education level, participants judged that monitoring robots were more beneficent than assistive robots and assistive robots more beneficent than companion robots. Assistive robots were perceived as more maleficent than monitoring robots and more than companion robots. Monitoring robots had more utility than companion robots and as a trend, assistive robots also had more utility than companion machines. Participants indicated a firmer intention to use monitoring than companion robots. All other comparisons were not significant.

With respect to education level, independent of robot type, level 4 students perceived more beneficence than level 3 students, whereas level 3 saw, as a trend, more maleficence than level 4 . Level 4 also assigned more utility to robots than level 3 students, and as a trend, level 4 deemed that robots increased the autonomy of patients, more so than level 2. 


\section{Conclusions}

The purpose of the current study was to determine which of the four principles of Beauchamp and Childress [18] were most prominent in the estimations of lower and middle vocational care students with regard to working with robots in their future care practice.

Overall, students scored Maleficence the lowest, meaning that care robots in general were not seen as pernicious. However, students of care also rated use intentions low, indicating poor motivation to actually use a robot in the future. Possible beneficent effects of care robots were received with relative neutrality, whereas the potential increase in a client's autonomy was deemed considerable. Highest scores were obtained for the utility of robots, which is surprising in view of the students' reluctance to use them. On the whole, level 4 students were slightly more positive than level 3 or 2 students with respect to beneficence, utility, and the client's autonomy. All students viewed companion robots as more beneficent than monitoring robots and monitoring robots more beneficent than assistive robots. Although regarded as more maleficent, monitoring and assisting machines were also seen as more useful.

In all, these care students saw little harm in robots, found them useful, and expected clients to become more independent because of them; on the other hand, they were quite hesitant about using robots in their future practice. It is possible that the perceived potential effectiveness of robots for their work practice was affected by fear of job loss.

\section{Discussion}

One might think that current students of care have already acquired so-called '21st century skills', that is, they would have "information literacy, media literacy, and information, communication and technology literacy" [29]. Additionally, if that is the case, so theory has it, perceived usefulness and a positive attitude toward technology should increase the intention to use technology. Indeed, computer self-efficacy can act as an antecedent for perceived usefulness and positive attitude towards computer use [30]. 93.6\% of our survey participants stated they were skilled computer users and $72.3 \%$ claimed to enjoy working with computers. Nevertheless, these 21st-century skilled students were not very eager to employ robots in their future work practice.

Admittedly, the vocational care students in this survey did not see much harm in care robots, for the patient that is. However, when it came to their future work practice, they were reluctant to envision employing care machines, in spite of their potential utility. Listed hereafter are a few possible explanations for this.

\section{Possible Explanations for the Hesitation in Using Care Robots}

Robots may not have been viewed as maleficent, but neither were they seen as being beneficial or helpful (beneficence was rated 'neutral'). Although useful for the instrumental side of nursing and caring (utility high), it might be that these students feared that robots would weaken the relationship between caregiver and care receiver (autonomy high), commonly considered fundamental to 'good care.' Hence, they were hesitant to work with robots. Lewis and West [31] state that the care relationship is crucial to securing care quality. If 'good care' depends substantially on the quality of the care relationship, then more attention should be paid to the human care workforce. Perhaps this was a principal concern of our sample of care students. Moreover, in covering the instrumental aspects of care, robots may also have been perceived as an occupational threat, making the nurse seem less important (e.g., when the client becomes attached to the robot) or even redundant.

On a societal plane, $70 \%$ of Europeans have a positive attitude towards robots in general [32]. However, when it comes to healthcare robots, they are not so positive. Only $22 \%$ of Europeans think that robots should be introduced in healthcare [32]. Sixty percent are even resentful of the prospect of robots caring for children and older adults [32]. Perhaps our care students were resonating with a more public trend, vented in the media and discussed at the coffee table. 
We did not find great differences between educational levels in the way they perceived care robots. It could be that the educational differences between lower and middle vocational care students are negligible. As an additional exploratory analysis, we combined levels 2 and 3 and compared them with level 4, performing chi-square analysis is (Table 3). We found that level 4 students perceived more beneficence in care robots. However, contrary to our expectations, they do not perceive less maleficence. Higher vocational students also perceived a greater utility in care robots than lower vocational students, however this higher perceived utility does not translate into a higher use intention. All care students expressed low use intentions, the potential utility of robots notwithstanding.

Table 3. Exploratory analysis.

\begin{tabular}{|c|c|c|c|c|}
\hline & Lower Vocational & Middle Vocational & Total & Chi-Square \\
\hline & Mean (SD) & Mean (SD) & Mean (SD) & \\
\hline \multicolumn{5}{|l|}{ Assistive } \\
\hline Beneficence & $3.54(1.14)$ & $3.62(1.02)$ & $3.58(1.08)$ & 35.80 \\
\hline Maleficence & $2.97(0.99)$ & $2.89(0.92)$ & $2.93(0.95)$ & 29.52 \\
\hline Autonomy & $3.72(0.88)$ & $3.83(0.84)$ & $3.78(0.86)$ & 43.20 \\
\hline Utility & $3.77(1.00)$ & $3.98(0.85)$ & $3.88(0.93)$ & 42.93 \\
\hline Use Intention & 3.07 (1.24) & $3.13(1.13)$ & $3.10(1.18)$ & 27.97 \\
\hline \multicolumn{5}{|l|}{ Monitoring } \\
\hline Beneficence & $3.67(1.10)$ & $3.87(1.02)$ & 3.77 (1.06) & 46.56 * \\
\hline Maleficence & $2.80(0.96)$ & $2.66(0.91)$ & 2.72 (0.93) & 34.24 \\
\hline Autonomy & $3.77(0.84)$ & $3.86(0.85)$ & $3.82(0.84)$ & 40.55 \\
\hline Utility & $3.88(0.92)$ & $4.08(0.89)$ & $3.98(0.91)$ & 44.19 * \\
\hline Use Intention & $3.07(1.20)$ & $3.27(1.16)$ & 3.17 (1.18) & 39.62 \\
\hline \multicolumn{5}{|l|}{ Companion } \\
\hline Beneficence & 3.53 (1.19) & $3.60(1.04)$ & 3.57 (1.11) & 33.73 \\
\hline Maleficence & $2.77(0.96)$ & $2.66(0.85)$ & $2.71(0.91)$ & 23.87 \\
\hline Autonomy & $3.81(0.79)$ & $3.90(0.78)$ & $3.86(0.79)$ & 42.67 \\
\hline Utility & $3.68(1.00)$ & $3.80(0.87)$ & $3.75(0.94)$ & 42.70 \\
\hline Use Intention & $2.97(1.23)$ & $2.96(1.17)$ & $2.97(1.20)$ & 42.16 \\
\hline
\end{tabular}

As advised by Holloway and Wheeler [33], it may be more worthwhile to turn to qualitative research approaches to resolve matters of change or conflict, particularly in care relations, and explore the behaviours, feelings, and experiences of care students in confrontation with robots on the work floor in more detail.

Trainee care professionals perceived particular types of robots differently in terms of occupational ethics and use. Our research challenge is to ascertain what these care professionals would want from an assistive or monitoring machine that is-in their eyes-potentially very useful and somewhat innocuous. Should a robot assistant have a moral reasoning system that tells it what is 'good care'? Should a monitoring device know what information is private and what should be disclosed to the nurses at the ward? Companion robots may be seen as beneficent, but how can they become more useful? Additionally, how should they behave such that they do not undermine the quality of the care relationship between humans? These are not questions of occupational ethics and utility alone, as their answers will encourage better partnerships between human caretakers and artificial systems of the future. More research is needed, with a more rigorous research methodology to truly obtain the objections raised by (trainee) caregivers to facilitate acceptability. It is stated in the literature [34] that healthcare robots can potentially enhance elderly well-being and decrease the workload on caregivers.

\section{Education could Make a Difference}

This study suggests that it would be wise to enrich the curriculum of intermediate care education with practical classes on the use and ethical implications of new care technology, particularly in the 
case of care robots. This is especially of interest in the intermediate vocational domain because this group will be the main supplier of direct care of older adults in the near future. It is important to ensure that the provided care is in line with the wishes and needs of our vulnerable older adults, but at the same time keeps the job satisfaction of our precious caregivers as high as possible, given the circumstances.

Author Contributions: Conceptualization: M.A.M.v.K.; methodology: J.F.H. and E.A.K.; software: data management and statistical analyses were performed in SPSS, version 21; validation: J.F.H. and E.A.K.; formal analysis: M.A.M.v.K., J.F.H., and E.A.K.; data collection: M.A.M.v.K.; resources: VU University Amsterdam; data curation: E.A.K.; writing-original draft preparation: M.A.M.v.K.; writing-review and editing: M.A.M.v.K., J.F.H., and E.A.K.; visualization: E.A.K.; supervision: E.A.K. and J.F.H.; project administration: VU University Amsterdam; funding acquisition: J.F.H.

Funding: This study is part of the SELEMCA project (Services of Electro-Mechanical Care Agencies, grant NWO 646.000.003), which was funded within the Creative Industry Scientific Programme (CRISP) and supported by the Dutch Ministry of Education, Culture and Science. The contribution of the first author was funded by a personal grant from the Central Board of Inholland, University of Applied Sciences.

Acknowledgments: We wish to thank the researchers of the SELEMCA group for their incisive and constructive remarks and Kees Nijhoff for support with the data analysis. All authors are responsible for the reported research and all participated in the conception and design of the study, the analysis and interpretation of the data, and drafting and revising of the manuscript. The first author, MK, collected the data. All authors approved the manuscript as submitted.

Conflicts of Interest: The authors declare no conflict of interest.

\section{Appendix A}

Examples of question items. Note: these items are translated from Dutch.

This robot could be:

\begin{tabular}{ll}
\hline Handy & Utility $1+$ \\
Clumsy & Utility $2-$ \\
Unusable & Utility $3-$ \\
Suitable for his work & Utility $4+$ \\
Harmful & Maleficence 1+ \\
Dangerous & Maleficence 2 + \\
Caring & Beneficence 1+ \\
\hline
\end{tabular}

This robot:

\begin{tabular}{ll}
\hline Does the patient well & Beneficence 2+ \\
Makes someone more independent & Autonomy $1+$ \\
Disadvantaged other patients & Justice $1-$ \\
Limits freedom of the patient & Autonomy $2-$ \\
Ensures that a patients can take better care of himself & Autonomy 3+ \\
Hurts the patient & Maleficence 3+ \\
Makes the patient independent & Autonomy $4-$ \\
Makes life worse & Maleficence $4+$ \\
Favours some patients & Justice 2 - \\
Split attention evenly & Justice 3 + \\
Increases the quality of life & Beneficence 3+ \\
Let the patient make its own choice & Justice $4+$ \\
\hline
\end{tabular}


I think that this robot:

\begin{tabular}{ll}
\hline Is not going to be used & Use Intention $1-$ \\
Makes life better & Beneficence $4+$ \\
Can help the patient & Beneficence $5+$ \\
Treats everybody equally & Justice $5+$ \\
Diminishes quality of life & Maleficence $5+$ \\
Diminishes self-reliance & Autonomy $5-$ \\
Makes no distinction between people & Justice $6+$ \\
Neglects the patient & Maleficence $6+$ \\
Returns freedom to the patient & Autonomy $6+$ \\
Is taking good care of the patient & Beneficence $6+$ \\
Does things behind your back & Justice 7 - \\
Limits the patient in his freedom of choice & Justice 8 - \\
\hline
\end{tabular}

Try to put yourself in the shoes of a professional care provider:

\begin{tabular}{|c|c|}
\hline With this robot I would like to work & Use Intention $2+$ \\
\hline This robot seems suitable for the job & Use Intention $3+$ \\
\hline I would like to use such a robot & Use Intention $4+$ \\
\hline I would leave the robot in the closet & Use Intention 5 - \\
\hline I rather do the work myself & Use Intention $6-$ \\
\hline Working with a robot takes time & Utility 5 - \\
\hline Working with a robot saves time & Utility $6+$ \\
\hline \multicolumn{2}{|c|}{$\begin{array}{l}\text { As extra control-question regarding Use Intention: "It is more than likely that I will use this robot in the } \\
\text { near future" (yes/no). }\end{array}$} \\
\hline
\end{tabular}

\section{References}

1. Bloom, D.; Chatterji, S.; Kowal, P.; Lloyd-Sherlock, P.; McKee, M. Macroeconomic implications of population ageing and selected policy response. Lancet 2015, 385, 649-657. [CrossRef]

2. Christensen, K.; Doblhammer, K.; Rau, R.; Vaupel, J. Ageing populations: The challenges ahead. Lancet 2009, 374, 1196-1208. [CrossRef]

3. Lindahl-Jacobsen, R.; Rau, R.; Canudas-Romo, V.; Jeune, V.; Lenart, A.; Christensen, K.; Vaupel, J. Rise, stagnation, and rise of Danish women's life expectancy. Proc. Natl. Acad. Sci. USA 2016, 113, 4005-4020. [CrossRef]

4. Schwiegelshohn, F.; Hubner, M.; Wehner, P.; Gohringer, D. Tackling the New Health-Care Paradigm Through Service Robotics: Unobtrusive, efficient, reliable and modular solutions for assisted-living environments. IEEE Consum. Electron. Mag. 2017, 6, 34-41. [CrossRef]

5. Giesbers, H.; Verwey, A.; de Beer, J.D. Vergrijzing Samengevat; Volksgezondheid Toekomst Verkenning. Nationaal Kompas Volksgezondheid [Aging in Summary; Public Health Future Exploration. National Compass Public Health]. 2013. Available online: http:/ / www.nationaalkompas.nl/bevolking/vergrijzing/ vergrijzing-samengevat/ (accessed on 28 November 2018).

6. Broadbent, E.; Stafford, R.; MacDonald, B. Acceptance of Healthcare Robots for the Older Population. Int. J. Soc. Robot. 2009, 1, 319-330. [CrossRef]

7. Bemelmans, R.; Gelderblom, G.; Jonker, P.; de Witte, L. Socially Assistive Robots in Elderly Care: A systematic Review into Effects and Effectiveness. J. Am. Med Dir. Assoc. 2012, 13, 114-120. [CrossRef]

8. Banks, M.; Willoughby, L.; Banks, W. Aninmal-Assisted Therapy and Loneliness in Nursing Homes: Use of Robotic versus Living Dogs. J. Am. Med Dir. Assoc. 2008, 9, 173-177. [CrossRef] [PubMed] 
9. Broekens, J.; Heerink, M.; Rosendal, H. Assistive Social Robots in Elderly Care: A Review. Gerontechnology 2009, 8, 94-103. [CrossRef]

10. Frennert, S.; Östlund, B.; Eftring, H. Would Granny let an assistive robot into her home? In International Conference on Social Robotics; Springer: Berlin/Heidelberg, Germany, 2012; pp. 128-137.

11. Klein, B.; Cook, G. Emotional Robotics in Elder Care-A Comparison of Findings in the UK and Germany. In International Conference on Social Robotics; Springer: Berlin/Heidelberg, Germany, October 2012; pp. 108-117.

12. Moyle, W.; Beattie, E.; Cooke, M.; Jones, C.; Klein, B.; Cook, C.; Gray, C. Exploring the Effect of Companion Robots on Emotional Expression in Older Adults with Dementia: A Pilot Randomized Controlled Trial. J. Gerontol. Nurs. 2016, 39, 46-53. [CrossRef]

13. Tamura, T.; Yonemitsu, S.; Itoh, A.; Oikawa, D.; Kawakami, A.; Higashi, Y.; Fujimoto, T.; Nakajima, K. Is an Entertainment Robot Useful in the Care of Elderly People With Severe Dementia? J. Gerontol. Ser. A 2004, 59, M83-M85. [CrossRef]

14. Lauckner, M.; Kobiela, F.; Manzey, D. 'Hey robot, please step back!'—Exploration of a spatial threshold of comfort for human-mechanoid spatial interaction in a hallway scenario. In Proceedings of the 23rd IEEE International Symposium on Robot and Human Interactive Communication: Human-Robot Co-Existence: Adaptive Interfaces and Systems for Daily Life, Therapy, Assistance and Socially Engaging Interactions (IEEE RO-MAN 2014), Edinburgh, UK, 25-29 August 2014; Institute of Electrical and Electronics Engineers: New York, NY, USA, 2014; pp. 780-787.

15. Van Kemenade, M.; Hoorn, J.; Konijn, E. Healthcare Students' Ethical Considerations of Care Robots in The Netherlands. Appl. Sci. 2018, 8, 1712. [CrossRef]

16. Ienca, M.; Jotterand, F.; Vica, C. Social and Assistive Robotics in Dementia Care: Ethical Recommendations for Research and Practice. Int. J. Soc. Robot. 2016, 8, 565-573. [CrossRef]

17. MBO Raad. Dutch VET. Retrieved from MBO Counsil. Available online: https://www.mboraad.nl/english (accessed on 27 September 2017).

18. Beauchamp, T.L.; Childress, J.F. Principles of Biomedical Ethics; Oxford University Press: Oxford, UK, 2013.

19. Yu, T.; Lin, M.; Liao, Y. Understanding factors influencing information communication technology adoption behavior: The moderators of information literacy and digital skills. Comput. Hum. Behav. 2017, 71, 196-208. [CrossRef]

20. Cook, N.; Winkler, S. Acceptance, Usability and Health Applications of Virtual Worlds by Older Adults: A Feasibility Study. JMIR Res. Protoc. 2016, 5, e81. [CrossRef]

21. Massimiliano, S.; Giuliana, M.; Fornara, F. Robots in a Domestic Setting: A psychological Approach. Univ. Access Inf. Soc. 2005, 4, 146-155.

22. CBS Statline 2018. MBO; Doorstroom en Uitstroom, Migratieachtergrond, Generatie, Regiokenmerken. 124 . November 19, 2018. [VET; Flow and Outflow, Migration Background, Generation, Regional Characteristics]. Available online: https:/ / statline.cbs.nl/StatWeb/publication/?VW=T\&DM=SLNL\&PA=71895NED\&D1= $\mathrm{a} \& \mathrm{D} 2=2,5,8,11 \& \mathrm{D} 3=2,8,10 \& \mathrm{D} 4=\mathrm{a} \& \mathrm{D} 5=0-1,3-4 \& \mathrm{D} 6=0 \& \mathrm{D} 7=0 \& \mathrm{D} 8=1 \& H D=101029-1031 \& \mathrm{HDR}=\mathrm{G} 6, \mathrm{G} 5, \mathrm{G} 7$, $\mathrm{G} 4, \mathrm{~T} \& \mathrm{STB}=\mathrm{G} 3, \mathrm{G} 1, \mathrm{G} 2$ (accessed on 14 January 2019).

23. MBO Raad-[Vocational Counsel]. Het MBO Feiten en Cijfers [The VET, Facts and Figures]. 2019. Available online: https://www.mboraad.nl/het-mbo/feiten-en-cijfers/mbo-scholen (accessed on 28 February 2019).

24. Rijksoverheid-[Dutch Government]. Onderwijs in Cijfers [Education in Figures]. 2018. Available online: https:/ / www.onderwijsincijfers.nl/kengetallen/mbo (accessed on 28 February 2019).

25. "Alice Cares" ["Ik ben Alice"]. Documentary, Directed by S. Burger. Keydocs/Doxy/NCRV. 2015. Available online: http:/ / www.ikbenalice.nl/ (accessed on 14 January 2019).

26. Taber, K. The use of Cronbach's alpha when developing and reporting research instruments in science education. Res. Sci. Educ. 2018, 48, 1273-1296. [CrossRef]

27. Adams, T. Gender and feminization in healthcare professions. Sociol. Compass 2010, 4, 454-465. [CrossRef]

28. Armstrong, R.A. When to use the Bonferroni correction. Ophthalmic Physiol. Opt. 2014, 34, 502-508. [CrossRef] 
29. Kurshan, M. Teaching 21st Century Skills For 21st Century Success Requires an Ecosystem Approach. 2017. Available online: https://www.forbes.com/sites/barbarakurshan/2017/07/18/teaching21st-century-skills-for-21st-century-success-requires-an-ecosystem-approach/\#1c5790f3fe64 (accessed on 28 November 2018).

30. Teo, T.; Zhou, M. Explaining the intention to use technology among university students: A structural equation modeling approach. J. Comput. High. Educ. 2014, 26, 124-142. [CrossRef]

31. Lewis, J.; West, A. Re-Shaping Social Care Services for Older People in England: Policy Development and the Problem of Achieving 'Good Care'. J. Soc. Policy 2014, 43, 1-18. [CrossRef]

32. Public Attitudes towards Robots; Special Eurobarometer 382; European Commission: Brussels, Belgium, 2012.

33. Holloway, I.; Wheeler, S. Qualitative Research in Nursing and Healthcare; Wiley-Blackwell: Oxford, UK, 2015.

34. Kachouie, R.; Sedighadeli, S.; Khosla, R.; Chu, M.T. Socially Assistive Robots in Elderly Care: A Mixed-Method Systematic Literature Review. Int. J. Hum. Comput. Interact. 2014, 30, 369-393. [CrossRef]

(C) 2019 by the authors. Licensee MDPI, Basel, Switzerland. This article is an open access article distributed under the terms and conditions of the Creative Commons Attribution (CC BY) license (http://creativecommons.org/licenses/by/4.0/). 